\title{
Inflammatory Bowel Diseases Prevalence in Patients Underwent Colonoscopy in Zagazig University Hospitals
}

\author{
Ehab F. Mostafa ${ }^{1}$, Ashraf Metwally, $\mathrm{MD}^{2}$ and Safa A. Hussein, $\mathrm{MD}^{3}$ \\ ${ }^{I}$ Internal Medicine Department, Faculty of Medicine, Zagazig University, Zagazig,Egypt. \\ ${ }^{2}$ Tropical Medicine Department, Faculty of Medicine, Zagazig University, Zagazig, Egypt \\ ${ }^{3}$ Community Medicine Department, Faculty of medicine, Zagazig University, Egypt
}

Corresponding Author

Ehab F. Mostafa, MD

Mobile:

$+201285692388$

E mail:

hobanoh@yahoo.com

Key words:

IBD, colonoscopy,

bleeding per rectum,

bowel habit

Short title: Prevalence of Inflammatory bowel diseases
Background and study aim: Colonoscopy is recommended by many international gastroenterology and cancer societies as the initial diagnostic modality for colorectal cancer. It is considered the most accurate diagnostic tool in inflammatory bowel disease. These are two identified subtypes of the disease, ulcerative colitis (UC) and Crohn's disease. The previous studies on Egyptian patients said that the incidence of IBD increased significantly in the past ten years. The aim of this study was to calculate the prevalence of IBD among patients referred to endoscopy units to perform colonoscopy and define the most common presenting symptoms of IBD. We also wanted to shed light on the most common presenting complaints that lead to referral to colonoscopy and the common colonic lesions that were diagnosed by colonoscopy.r
Patients and Methods: Cross sectional study involved 250 patients who underwent colonoscopy in the period from November 2014 to November 2015, the presenting complaint was recorded as well as the results of colonoscopy.

Results: Bleeding per rectum was the commonest indication for colonoscopy (46\%) followed by chronic abdominal pain $(20 \%)$, then chronic diarrhea $(17 \%)$. The commonest pathological conditions were internal hemorrhoids in $27.6 \%$ followed by nonspecific colitis in $20.4 \%$, ulcerative colitis in $10.4 \%$, carcinoma in $10.4 \%$, Crohn's in $0.8 \%$ then polyps in $0.4 \%$. $\mathrm{UC} / \mathrm{CD}$ ratio was 13:1.

Conclusion: In a group of Egyptian patients undergoing colonoscopy the most frequent diagnosis were internal piles, non-specific colitis followed by inflammatory bowel disease with a prevalence of $11.2 \%$ and predominance of UC over CD.

disease (CD). In the Western countries, the incidence and prevalence of inflammatory bowel diseases has increased in the past 50 years, up to 8$14 / 100,000$ and 120-200/100,000 persons, respectively, for ulcerative colitis (UC) but $6-15 / 100,000$ and 50-200/100,000 persons, respectively, for Crohn's disease (CD) [2]. IBD have also emerged in countries in which it had rarely been previously reported, including South Korea, China, India and North Africa [3]. The incidence in the Mediterranean countries is about 5/100,000 persons [4]. The epidemiological characters of IBD in Egypt is similar to those in Asian and African population with $\mathrm{UC} / \mathrm{CD}$ ratio of $6: 1$. The incidence in Egypt has increased in the past ten years $[\mathbf{5 , 6}]$. 
This study was conducted to calculate the prevalence of IBD among patients referred to endoscopy units to perform colonoscopy and evaluate the most common presenting symptoms of IBD. We also wanted to shed light on the most common presenting complaints for which colonoscopy was initially done and the most common colonic diseases that can be diagnosed by colonoscopic examination.

\section{PATIENTS AND METHODS}

This cross sectional observational study was carried out in Internal Medicine and tropical medicine Departments, endoscopy units, Zagazig University Hospitals from November 2014 to November 2015 on all consecutively enrolled patients admitted to the Endoscopy Units for colonoscopy complaining of various lower GIT symptoms (250 patients).

\section{Inclusion criteria}

Patients referred to endoscopy units in Zagazig university hospitals during the period of the study.

\section{Exclusion criteria:}

- Patients $<18$ and $>80$ years

- Patients who didn't give consent to participate in the study

- Patients with failure of colonoscopy to reach the iliocaecal valve

- Patients with contraindications of colonoscopy e.g. suspected colonic perforation, acute peritonitis, pregnancy, severe bleeding tendency, shock, uncooperative patient and if toxic mega colon is suspected were excluded

All patients were subjected to the following:

- Detailed history with special stress on symptoms of IBD as (bleeding per rectum, chronic diarrhea, tenesmus and chronic dysentery) and symptoms of extra-intestinal manifestations as (ophthalmic, musculoskeletal, mucocutaneous)

- Thorough clinical examination
- Colonoscopy was done by two senior experts by OLYMPUS GIF -CF140 videoscope

Preparation of the patients for colonoscopy was done as the follow:

The patient was asked not to take any solid foods for 3 days before the procedure only fluids water and clear juices, The day before the colonoscopy, the patient was given a laxative preparation MOVIPREP (polyethylene glycol 3350, sodium sulfate, sodium chloride, potassium chloride, sodium ascorbate, and ascorbic acid) for Oral Solution which were tolerable and effective in most of our patients.

Sedation of the patients before colonoscopy: During the procedure the patient is often given sedation intravenously, employing agents such as fentanyl or midazolam. The average person will receive a combination of these two drugs, usually between 25 to $100 \mu \mathrm{g}$ IV fentanyl and 5-10 mg IV midazolam.

The procedure: The first step is usually a digital rectal examination, to detect anal stricture or any rectal mass and to determine if preparation has been inadequate. The endoscope is then passed through the anus up the rectum, the colon (sigmoid, descending, transverse and ascending colon, the cecum), and ultimately the terminal ileum. Multiple biopsies were taken from pathologic lesion for histopathology.

\section{Histopathological examination}

The biopsy was referred to one expert pathologist and the following steps were done. Fixation, processing, embedding, sectioning and staining with hematoxylin and eosin.A preliminary survey was conducted. Diagnosis of IBD had to satisfy accepted clinical and endoscopic criteria with histological confirmation.

Patients were divided into two groups according to colonoscopy and pathological examination of their biopsies.

Group I: included 222 patients without IBD Group II: included 28 patients diagnosed with IBD 
The severity of IBD was classified according to the Montreal classification for severity of IBD [7]

\begin{tabular}{|l|l|l|}
\hline Extent $\begin{array}{l}\text { E3 } \\
\text { Pancolitis or extensive } \\
\text { colitis: involvement } \\
\text { extends proximal to } \\
\text { splenic flexure }\end{array}$ & E2 & Proctitis: Limited to the rectum distal to rectosigmoid junction \\
\hline Severity & S0 & Clinical remission: Asymptomatic \\
\cline { 2 - 3 } & S1 & $\begin{array}{l}\text { Mild UC: passage of four or fewer stools/day with or without blood with } \\
\text { absence of any systemic illness and normal inflammatory markers }\end{array}$ \\
\cline { 2 - 3 } & S2 & $\begin{array}{l}\text { Moderate UC: passage of more than four stolls /day with minimal signs of } \\
\text { systemic toxicity }\end{array}$ \\
\cline { 2 - 3 } & S3 & $\begin{array}{l}\text { Severe UC: passage of at least 6 bloody stool/day with pulse }>90 \mathrm{bpm}, \\
\text { temperature }>37.5, \text { hemoglobin }<10 \mathrm{~g} / \mathrm{dl}, \text { ESR }>30 \mathrm{~mm} / \mathrm{h}\end{array}$ \\
\hline
\end{tabular}

\section{Statistical analysis}

The collected data were analyzed by computer using a data base software program, Statistical Package of Social Services version 16and Epidemiological Information Package (EPi-Info) version 6.04. Qualitative data were represented as frequencies\& percentages while quantitative data were represented by mean and standard deviation. Comparison of quantitative variables was done using $t$ test while comparison was done using Chi-square for categorical data. The results were considered statistically significant when the significant probability was less than or equal to $(\mathrm{p} \leq 0.05)$.

Ethical Consideration: The study was approved by the institutional review board in faculty of Medicine, Zagazig University.

\section{RESULTS}

Table 1 shows the distribution of demographic data among all patients of the study and reveals that males represented $66 \%$ of the sample. The percent of smokers was $27 \%$ and all comorbidities were nearly equally presented in the sample. Table 2 shows that bleeding per rectum was the most common presenting symptom among all patients admitted to colonoscopy followed by abdominal pain. Table 3 shows that the most common diagnosis was internal hemorrhoids followed by non-specific colitis and in $20 \%$ of cases the colonoscopic examination was normal. IBD was evident in $11.2 \%$ of cases, ulcerative colitis represented most of them $(10.4 \%)$ while Crohn's disease was evident in just two cases in the sample with percent of $0.8 \%$.This means that the $\mathrm{UC} / \mathrm{CD}$ ratio is $13: 1$.

Table (4) shows that with comparison between the IBD patients and other patients showed that they were significantly younger and the percentage of females among them was significantly higher and the percentage of smokers and comorbidities also was significantly lower. Table 6 shows that most cases of ulcerative colitis had only proctitis about $50 \%$, with mild severity $42 \%$. And only five cases had dysplastic changes evident in their biopsies. Comparison between IBD patients as regards the most common presenting symptoms we found that the most common presenting symptom among them was bleeding per rectum followed by chronic dysentery and chronic diarrhea. The frequency of all symptoms was significantly higher among patients with IBD except for bleeding per rectum which showed no significant difference as seen in table 5.Table 6 shows the different severity and extent of UC showing that nearly half of the patient had mild disease that was restricted to the rectum. 
Table (1): Demographic data of the studied group

\begin{tabular}{|l|l|c|c|}
\hline \multirow{2}{*}{ Age (years) } & Mean \pm SD & $42.89 \pm 14.0$ \\
\cline { 2 - 4 } & Median (Range) & $42.0(18-80)$ & \% \\
\hline \multirow{3}{*}{ Sex } & Female & $\mathbf{N}$ & 34.0 \\
\cline { 2 - 4 } & Male & 85 & 66.0 \\
\hline \multirow{3}{*}{ Special habits } & Smoker & 165 & 27.2 \\
\cline { 2 - 4 } & X-smoker & 68 & 0.8 \\
\hline \multirow{5}{*}{ Comorbidities } & Chronic liver disease & 2 & 4.4 \\
\cline { 2 - 4 } & Diabetes & 11 & 6.0 \\
\cline { 2 - 4 } & Hypertension & 15 & 6.0 \\
\cline { 2 - 4 } & Polyarthritis & 15 & 0.4 \\
\cline { 2 - 4 } & Total & 43 & 17.2 \\
\hline
\end{tabular}

Table (2): The main presenting symptoms that were reported by the patients of the studied group

\begin{tabular}{|l|c|c|}
\hline & No & \% \\
\hline Bleeding per rectum & 115 & 46.0 \\
\hline Chronic abdominal pain & 50 & 20.0 \\
\hline Chronic diarrhea & 42 & 16.8 \\
\hline Chronic constipation & 32 & 12.8 \\
\hline Chronic dysentery & 18 & 7.2 \\
\hline Fever & 2 & 0.8 \\
\hline Weight loss & 32 & 12.8 \\
\hline Anemia & 5 & 2.0 \\
\hline Melena with free UGI endoscopy & 1 & 0.4 \\
\hline
\end{tabular}

Table (3): The distribution of final diagnosis after colonoscopy and pathological examination among patients of studied group

\begin{tabular}{|l|c|c|}
\hline \multicolumn{1}{|c|}{ Diagnosis } & No & \% \\
\hline Internal piles & 69 & 27.6 \\
\hline Anal fissure & 11 & 4.4 \\
\hline Polyposis & 15 & 6 \\
\hline Diverticulosis & 5 & 2 \\
\hline Non-specific colitis & 51 & 20.4 \\
\hline Free colonoscopy & 50 & 20 \\
\hline IBD (total) & 28 & 11.2 \\
\hline Ulcerative colitis & 26 & 10.4 \\
\hline Crohn's disease & 2 & 0.8 \\
\hline Colorectal cancer & 39 & 15.6 \\
\hline
\end{tabular}


Table (4): Comparison between group I and group II as regards demographic data

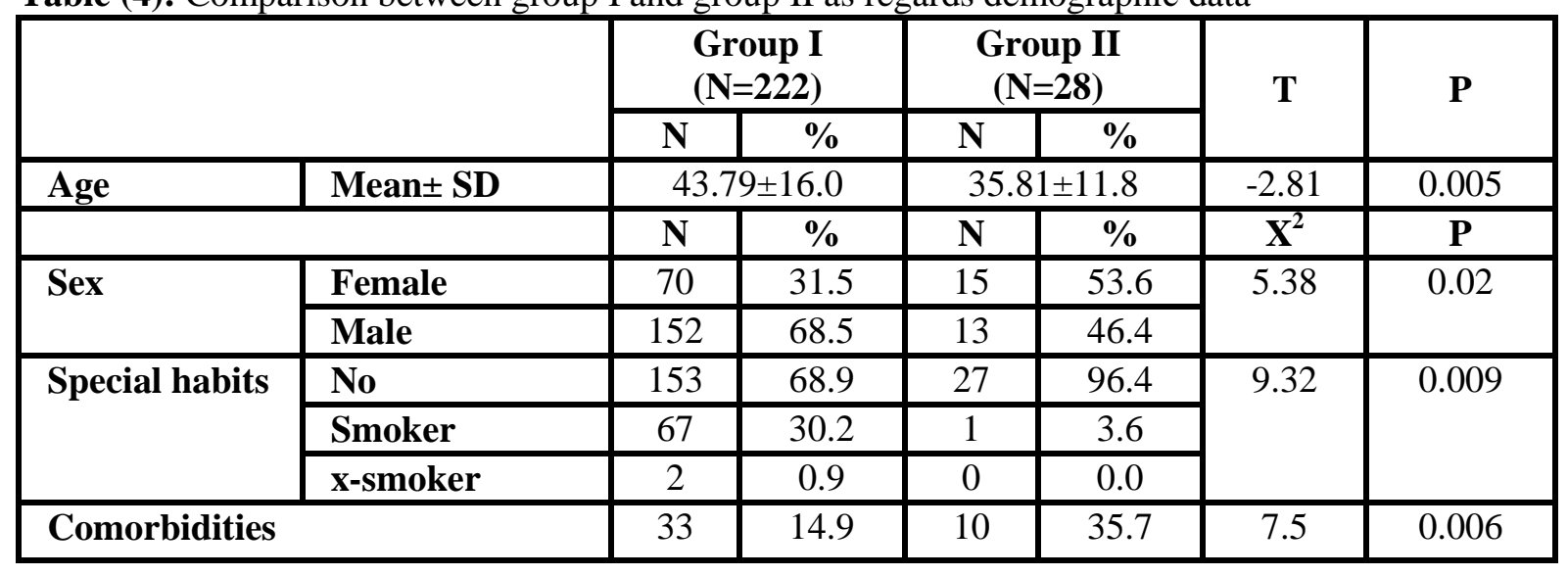

Table (5): Comparison between the studied groups as regards the presenting symptoms

\begin{tabular}{|l|c|c|c|c|}
\hline \multicolumn{1}{|c|}{ Symptom } & $\begin{array}{c}\text { Group I } \\
(\mathbf{N = 2 2 2})\end{array}$ & $\begin{array}{c}\text { Group II } \\
(\mathbf{N = 2 8})\end{array}$ & $\mathbf{X}^{\mathbf{2}}$ & $\mathbf{P}$ \\
\hline Bleeding per rectum & $98(44.1 \%)$ & $17(60.7 \%)$ & 2.748 & 0.974 \\
\hline Chronic dysentery & $4(1.8 \%)$ & $13(46.4 \%)$ & 78.133 & 0.00001 \\
\hline Chronic diarrhea & $29(13.06 \%)$ & $13(46.4 \%)$ & 19.803 & 0.00001 \\
\hline Abdominal pain & $38(17.1 \%)$ & $12(42.8 \%)$ & 10.296 & 0.001 \\
\hline Fever & $1(0.5 \%)$ & $2(7.1)$ & 9.3929 & 0.002 \\
\hline Weight loss & $21(9.4 \%)$ & $11(39.2 \%)$ & 19.8172 & 0.00001 \\
\hline Anemia & $1(0.4 \%)$ & $4(14.2 \%)$ & 24.282 & 0.00001 \\
\hline
\end{tabular}

Table (6): Classification of ulcerative colitis according to Montreal classification and microscopic findings

\begin{tabular}{|l|l|c|c|}
\hline & & $\mathbf{N = 2 6}$ & \% \\
\hline \multirow{4}{*}{ Extent } & E1 & 13 & 50 \\
\cline { 2 - 4 } & E2 & 7 & 26.9 \\
\cline { 2 - 4 } & E3 & 6 & 23.1 \\
\hline \multirow{4}{*}{ Severity } & S1 & 11 & 42.3 \\
\cline { 2 - 4 } & S2 & 8 & 30.7 \\
\cline { 2 - 4 } & S3 & 7 & 26.9 \\
\hline \multirow{3}{*}{ findings } & Ulceration & 26 & 100 \\
\cline { 2 - 4 } & Crypt abscess & 26 & 100 \\
\cline { 2 - 4 } & Mucosal neutrophil infiltration & 26 & 100 \\
\cline { 2 - 4 } & Dysplastic changes & 5 & 19.2 \\
\hline
\end{tabular}

\section{DISCUSSION}

Colonoscopic procedure is an accepted modality for evaluation of colonic disease, the demand for colonoscopy has been increasing over years, with the decline in complications rate associated with the procedure [8]. Colonoscopy may be carried out for a variety of reasons such as to investigate the cause of gastrointestinal haemorrhage, abdominal pain, unexplained changes in bowel habit, suspicious of malignancy or an abnormality found in ultrasound, individuals with a previous history of polyps, cancer colon and those with a family history of cancer colon may also undergo periodic colonoscopies [9].

We conducted this study to determine the prevalence and clinical characteristics of IBD in all patients who done colonoscopy at Internal Medicine and Tropical medicine Departments 
endoscopy units, Zagazig university hospitals in the period from November 2014 to November 2015. Bleeding per rectum was the most common presenting complaint for colonoscopy in 115 patients $(46 \%)$ followed by chronic abdominal pain 51 patients (20\%), chronic diarrhea 42 patients (17\%) and chronic constipation in 32 patients (13\%). This agrees with Dabuka et al. [11] who said that bleeding per rectum and abdominal pain are common problems that prompt patients to seek medical help and that rectal bleeding is an early sign for many gastrointestinal disorders including colorectal cancer and inflammatory bowel disease.

In developing countries like Egypt, infective diarrhea and dysentery are still common.In this study $16.8 \%$ of our patients were presenting with chronic diarrhea and $2 \%$ only with chronic dysentery similar results were observed by Goenka et al. [12]. Similar results were shown by Sahu et al. [13], Elbatea et al. [5] and Olokoba et al. [9]. Against our results a study done by Alshamali et al. [8] who reported that lower abdominal pain is the main complaint in 53\% of cases admitted for colonoscopy. Racial and geographical variations may be the reason for this difference.

In our study, the commonest pathologies seen at colonoscopy were internal hemorrhoids $27.6 \%$ followed by non-specific colitis $20.4 \%$,ulcerative colitis $10.4 \%$, carcinoma $10.4 \%$, Crohn's $0.8 \%$ then polyp $0.4 \%$. This spectrum of pathologies is similar to Ismaila and Misuno [14] who found hemorrhoids to be the commonest lesion whereas Olokoba et al. [9] reported that the commonest pathologies found at colonoscopy were cancer colon followed by diverticulosis and polyps.

Patients with IBD in our study were significantly younger and the female to male ratio was $1.15: 1$ this is significantly higher than seen in the percentage encountered in non-IBD patients, this agrees with Esmat et al. [6] whose study find the female to male ratio is $1: 1.15$. However, the mean presenting age in our study is $35 \pm 11$ that is about six years older than stated by Esmat et al. [6]. This agrees with Tozun et al. [15] who said that most patients are diagnosed between age of 20 to 40 years.

The percent of smokers among the IBD is very much lower than seen in non-IBD patients may be due to the anti-inflammatory effect of Nicotine. This disagrees with Gearry et al., [16] who said that smoking can be a risk factor for IBD.
The frequency of co-morbidities is higher among IBD patients than in non-IBD this can be explained by the fact that IBD has many extraintestinal manifestations.

In our study the patients with IBD had significantly higher frequency of all symptoms except bleeding per rectum. The finding that can mean that the bleeding per rectum despite being the most annoying and the most common presenting complaint for colonoscopic examination, it's equally linked to all serious colonic diseases and cannot be linked specifically to any one of them.

In our study also we found that UC was more predominant than $\mathrm{CD}$, this actually coincides with most of the literature from worldwide that says that the incidence of ulcerative colitis is greater than that of Crohn's [2]. Our finding coincides with this data and similar to that of Esmat et al. [6] who observed a ratio of 6:1 for ulcerative colitis to Crohn's and reported that the incidence of IBD seem to be rising in Egypt.

The severity of disease at clinical presentation is important in determining the appropriate therapy ,according to Montreal classification our study revealed that $42.3 \%$ of our patients had mildly active disease at presentation ,30.7\% suffered from moderately active disease and $26.9 \%$ had sever disease.

In our study the histopathological examinations of biopsies showed that nearly all of ulcerative colitis patients had mucosal ulceration, crypt abscesses and submucosal infiltration with neutrophils and that mean, all our patients were in disease activity. $19.2 \%$ had dysplastic changes which was similar to results done by Kleer et al. [17] about the colorectal involvement in ulcerative colitis .in contrast to a study by Ritley et al. [18] which 58\% had crypt architectural irregularities. In addition, $32 \%$ had evidence of acute inflammatory activity: $28 \%$ acute inflammatory cell infiltrate, $11 \%$ crypt abscesses, and $22 \%$ mucin depletion.

\section{CONCLUSION}

In our cohort of Egyptian patients subjected to colonoscopy, the prevalence of IBD was calculated to equal $11.2 \%$. The most frequent diagnoses were internal hemorrhoids, non-specific colitis followed by inflammatory bowel disease. Many features of IBD were similar to IBD in the west countries, but these were notable difference as 
the female preponderance for $\mathrm{UC}$ and few extra intestinal manifestations. Only few of our patients had a family history and most patients with UC had mild to moderate disease affecting mainly the rectum and left sided disease

Funding: None.

Conflicts of interest: None.

Ethical approval:Approved ; written consents have been taken from all included patients.

\section{REFERENCES}

1. Bhagatwala J. Colonoscopy-indications and contraindications. Ettarh R, ed. Screening for Colorectal Cancer with Colonoscopy. 3rd ed. Rijeka, Croatia: In Tech; 2015.

2. Cosnes J, Gower-Rousseau C, Seksik P. Epidemiology and natural history of inflammatory bowel diseases. Gastroenterology 2011; 140: 1785-1794

3. Yang S, Hong W, Min Y, Kim H, Yoo J, Rhee P, et al. incidence and prevalence of ulceative colitis in the songpa-kangdorg district Seoul Korea ,1986-1997. J Gastroenterolhepatol 2000 ; 15 :1037-1042

4. Tezel A, Dökmeci G, Eskiocak M, Umit H, Soylu A. Epidemiological features of ulcerative colitis in Trakya, Turkey. J Int Med Res. 2003; 31:141148.

5. Elbatea H, Enaba M, Elkassas G, El-Kalla F, Elfert A. Indications and outcomes of colonoscopy in the middle of Nile delta of Egypt. Dig Dis Sci. 2011;56:2120-3

6. Esmat S, Mohamed N, Mohamed E, Yehia E, Mazen N. Epidemiological and clinical characteristics of inflammatory bowel diseases in Cairo, Egypt. World J Gastroenterol 2014 ; 20(3): 814-821

7. Silverberg M, Jack S, Tariq A, Ian A, Charles $N$ Bernstein, Steven R Brant, et al. Toward an integrated clinical, molecularand serological classification of inflammatory bowel disease: report of a working party of the Montreal world congress of gastroenterology. Can J Gasroentrol $2005 ; 19,5-36$.

8. Al-Shamali M, Kalaoui M, Hasan F. Colonoscopy: Evaluating indications and diagnostic yield. Ann Saudi Med 2001;21:304-7

9. Olokoba A, Olusegun A, Mathew O, Samuel A, Oladimeji A, Lateefat B. Indications and findings at colonoscopy in Ilorin, Nigeria Niger Med $\mathrm{J}$. 2013; Mar-Apr; 54(2): 111-114

10. Button L, Roberts S, Goldacre M. Hospitalized prevalence and 5-year mortality for IBD: record linkage study. World J Gastroenterol 2010; 16: 431-438

11. Dakubo J, Kumoji R, Naaeder S, Clegg L. Endoscopic evaluation of the colorectum in patients presenting with haematochaezia in at Korle-Bu Teaching Hospital Accra. Ghana Med J 2008; 42:33-7

12. Goenka M, Kochhar R, Mehta S. Spectrum of lower gastrointestinal hemorrhage: an endoscopic study of 166 patients. Indian J Gastroenterol 1993;12:129-31

13. Sahu S, Husain M, Sachan P. Clinical spectrum and diagnostic yield of lower gastrointestinal endoscopy at a tertiary centre. Internet $J$ Surg. 2009; 18

14. Ismaila B, Misauno M. Colonoscopy in a tertiary hospital in Nigeria. J Med Trop 2011;13:172-4

15. Tozun N, Atug O, Imeryuz N, Hamzaoglu HO, Tiftikci A, Parlak E.Clinical characteristics of inflammatory bowel disease in Turkey: a multicenter epidemiologic survey. J Clin Gastroenterol. 2009 Jan; 43(1):51-7

16. Gearry R, Richardson A, Frampton C, Dodgshun A, Barclay M. Population-based cases control study of inflammatory bowel disease risk factors. J Gastroenterol Hepatol. 2010;25(2):325-33.

17. Kleer C, Appelman H. Ulcerative colitis: patterns of involvement in colorectal biopsies and changes with time Am J Surg Pathol 1998;22(8):983-9

18. Ritley S, Mani V, Goodman M. Microscopic activity in ulcerative colitis: what does it mean Gut 1991;32,174-178 